\title{
Note on the application of planar-fit rotation for non-omnidirectional sonic anemometers
}

\author{
M. Li ${ }^{1}$, W. Babel ${ }^{2}$, K. Tanaka ${ }^{3}$, and T. Foken ${ }^{2,4}$ \\ ${ }^{1}$ Cold and Arid Regions Environmental and Engineering Research Institute, Chinese Academy of Sciences, Lanzhou, China \\ ${ }^{2}$ Department of Micrometeorology, University of Bayreuth, Bayreuth, Germany \\ ${ }^{3}$ Hiroshima Institute of Technology, Hiroshima, Japan \\ ${ }^{4}$ Member of Bayreuth Centre of Ecology and Environmental Research (BayCEER) of the University of Bayreuth, \\ Bayreuth, Germany
}

Correspondence to: W. Babel (wolfgang.babel@uni-bayreuth.de)

Received: 12 April 2012 - Published in Atmos. Meas. Tech. Discuss.: 1 October 2012

Revised: 17 January 2013 - Accepted: 20 January 2013 - Published: 5 February 2013

\begin{abstract}
For non-omnidirectional sonic anemometers like the Kaijo-Denki DAT 600 TR61A probe, it is shown that separate planar-fit rotations must be used for the undisturbed (open part of the sonic anemometer) and the disturbed sector. This increases the friction velocity while no effect on the scalar fluxes was found. In the disturbed sector, irregular values of $-\overline{u^{\prime} w^{\prime}}<0$ were detected for low wind velocities. Up to a certain extent these results can be transferred to the CSAT3 sonic anemometer (Campbell Scientific Ltd). This study was done for data sets from the Naqu-BJ site on the Tibetan Plateau.
\end{abstract}

\section{Introduction}

The planar-fit method (Wilczak et al., 2001) was developed to allow for the use of the eddy-covariance technique in a heterogeneous landscape with a non-uniform wind field and to align the sonic anemometer with the streamlines of this wind field (Finnigan, 2004; Foken et al., 2012a; Rebmann et al., 2012). The rotation angles must be calculated for a long-term data set of some weeks or months duration. This time period must be carefully determined depending on the structure of the underlying surface and the time of the year, including typical wind speeds and stratifications (Siebicke et al., 2012). Before the planar-fit method (PF) had come to the community's attention, the double rotation, described e.g. by Kaimal and Finnigan (1994), was predominantly used to remove mean vertical wind components in eddy-covariance data processing. It forces the mean vertical wind velocity to zero, independently for each single averaging period. Therefore, the double rotation is a very efficient method and it can be used for real time flux calculations (Rebmann et al., 2012). The planar-fit method is preferred now in the community, as it overcame the deficiencies related to the double rotation method. Basically, these are potential overrotation, information loss, deterioration of data quality and a nonconsistent reference surface on timescales beyond the averaging period, which is required for seasonal of annual budget estimations (Wilczak et al., 2001; Lee et al., 2004; Foken et al., 2004; Rebmann et al., 2012). Especially in complex landscapes and over tall vegetation, the vertical wind velocity may not always be zero for 30-min averages, which has to be taken into account (Lee, 1998; Paw U et al., 2000; Finnigan et al., 2003). In many cases, however, the terrain structure is too complex to be levelled on a plane by a single planar-fit rotation. Finnigan et al. (2003) mention a dependence of the rotation angle on wind direction for such cases, which can be realized, e.g. by a sector-wise planar-fit. This has been proposed by Foken et al. (2004) and already adopted, e.g. by Ono et al. (2008), Yuan et al. (2011), and Siebicke et al. (2012).

The planar-fit method is ideally suited for omnidirectional sonic anemometers like USA-1 (Metek GmbH), R3 (Gill Instruments Ltd.) and others. For this type of sensors, no wind sector is significantly influenced by flow distortion. Therefore, the rotation follows the wind field and should not be affected by sonic anemometer structures. Nevertheless, an 
influence of such structures can also be found for omnidirectional sonic anemometers (Göckede et al., 2008), but often these are symmetric in three or four directions. This is not the case for sonic anemometers with an open measuring sector and a disturbed sector due to the anemometer mounting structure (Dyer, 1981). A classical representative of this anemometer type is the DAT 600 with the so-called TR61Aprobe, produced by Kaijo-Denki, Japan (Fig. 1a, Hanafusa et al., 1982), which is still in use. The most commonly currently used example is the CSAT3, produced by Campbell Scientific Ltd., USA (Fig. 1b).

The non-omnidirectional sonic anemometer has two sectors: the disturbed sector and the undisturbed measuring sector with nearly no flow distortion. The undisturbed (open) sector extends from its centre $\pm 60^{\circ}$ for the Kaijo-Denki TR61A-probe (Fig. 1a), and $\pm 170^{\circ}$ in the case of the CSAT3 (Fig. 1b, any direction except flow from the back side). The disturbed sector for CSAT3 was confirmed to be approximately $\pm 20^{\circ}$ in wind tunnel measurements (Friebel et al., 2009). Field measurements typically show a standard deviation for wind direction of $\pm 20^{\circ}$, which is also found in the data sets used for this study. It is usually recognised in flux processing to exclude the disturbed sector in the back of the CSAT3 measuring paths (Foken et al., 2004). The opposite sector, when the wind passes the measuring paths before encountering the CSAT3 mounting structure (front sector), is usually not considered as disturbed in flux processing. Siebicke and Serafimovich (2007) can confirm a strong effect on wind velocities in the back sector of a CSAT3, but also a weak effect of the front sector on low wind velocities in a wind tunnel study.

To account for these instrument-specific characteristics combined with the standard deviation of wind direction, the undisturbed sector is assumed to be $\pm 40^{\circ}$ for DAT 600 and $\pm 150^{\circ}$ for CSAT3 in the following analyses, and the CSAT3 front sector will be handled separately. When using the planar-fit method for the whole wind sector, the determination of the regression coefficients (and therefore rotation angles) is influenced by the disturbed flow due to sensor structure. Hence the flux calculation is based on a wrong coordinate system. As this problem is often not considered in flux processing, we will discuss the effect when correctly applying the planar-fit method for the undisturbed sector only.

The Kaijo-Denki sonic anemometer must normally be used together with a rotator and moved into the mean wind direction for each measuring series (Foken et al., 1988). If this is not done, the results are significantly influenced in the $240^{\circ}$ disturbed sector. A typical error is the occurrence of negative frictions, $-\overline{u^{\prime} w^{\prime}}<0$ (Gerstmann and Foken, 1984), where $w^{\prime}$ and $u^{\prime}$ are the fluctuations of the vertical wind component and the horizontal wind component, respectively; the latter is aligned into the mean wind direction. The anemometer is typically rotated into the mean wind direction and $-\overline{v^{\prime} w^{\prime}} \approx 0\left(v^{\prime}\right.$ wind component perpendicular to the mean wind direction). It follows for continuity reasons that $-\overline{u^{\prime} w^{\prime}}>0$. A self-correlation, however, occurs between $u^{\prime}$ and $w^{\prime}$ due to flow distortion mainly in the case of low wind speeds, creating irregular friction values. Similar errors were also found in the data set of the CAMP/Tibet (Coordinated Enhanced Observing Period (CEOP), Asia-Australia Monsoon Project (CAMP) on the Tibetan Plateau) experiment (Li et al., 2006). Furthermore, for earlier experiments at this site in 1998 and 2002, Hong et al. (2004) reported unexplained differences of the wind measurements with the Kaijo-Denki TR61A-probe and the CSAT3.

\section{Material and methods}

For this study, two well-analysed and quality-checked data sets from 6 February to 30 September 2008 (data set A) and from 14 May to 25 June 2010 (data set B), with half hour values of the calculated fluxes, were used. These data sets have been examined in preference to an earlier data set of CAMP/Tibet from 12 April 2004 to 3 September 2007 at the Naqu-BJ site ( $91^{\circ} 48^{\prime} 59^{\prime \prime} \mathrm{E}, 31^{\circ} 18^{\prime} 42^{\prime \prime} \mathrm{N}, 4502 \mathrm{~m}$ a.s.1.), where we already found negative friction for about $50 \%$ of the data. Like during CAMP/Tibet, the Kaijo-Denki DAT 600 TR61A probe sonic anemometer was installed at $20 \mathrm{~m}$ height on a tower orientated to a westerly direction $\left(270^{\circ}\right.$, Fig. 1c) for data set A. Data set B also stems from the Naqu-BJ site, but was a direct comparison of the Kaijo-Denki DAT 600 TR61A probe (orientation $263^{\circ}$ ) and the Campbell CSAT3 (orientation $213^{\circ}$ ) at a measuring height of $3.02 \mathrm{~m}$ (Fig. 1d). The Naqu-BJ site is located on a flat grassland $(5 \mathrm{~cm}$ high during the monsoon season) near Nagqu city. The Nagqu area lies in the sub-frigid climatic zones, and annual mean temperature ranges from $-0.9^{\circ} \mathrm{C}$ to $-3.3^{\circ} \mathrm{C}$. The landscape is very flat (incline $<2^{\circ}$ ), and gentle hills occur in NNW-NE of the measurement location; the shortest distance to the hill slope is $900 \mathrm{~m}$ in NNE (Fig. 1c). Other hills and mountains in sectors $\mathrm{E}, \mathrm{S}$, and $\mathrm{W}$ are at least $10 \mathrm{~km}$ away from the eddycovariance setup (south-west sector is shown in Fig. 1d). Thus a possible terrain influence on the wind field can be neglected, and the deviations from its ideal behaviour can be attributed to sensor structures and the influence of the tower.

The data were analysed with the software package TK2/TK3 (Mauder and Foken, 2004, 2011; Mauder et al., 2008), which offers the possibility of applying the planarfit method sector-wise within a given data set. The applied corrections were done in the software package according to Foken et al. (2012b).

The planar-fit method was applied for (i) the whole data set, and (ii) separately for the undisturbed and the disturbed sector. The undisturbed sector of the DAT 600 sonic anemometer was defined as $\pm 40^{\circ}$ from the centre of the undisturbed sector. For CSAT3 we used $\pm 150^{\circ}$, but separated the front sector, selected as $\pm 30^{\circ}$. This sector is positively rated by the community in general but shows weak influence of sensor structure. Hence the front sector is rotated 
(a)

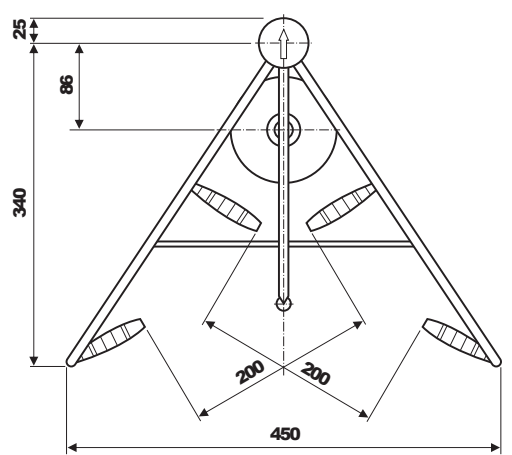

(b)
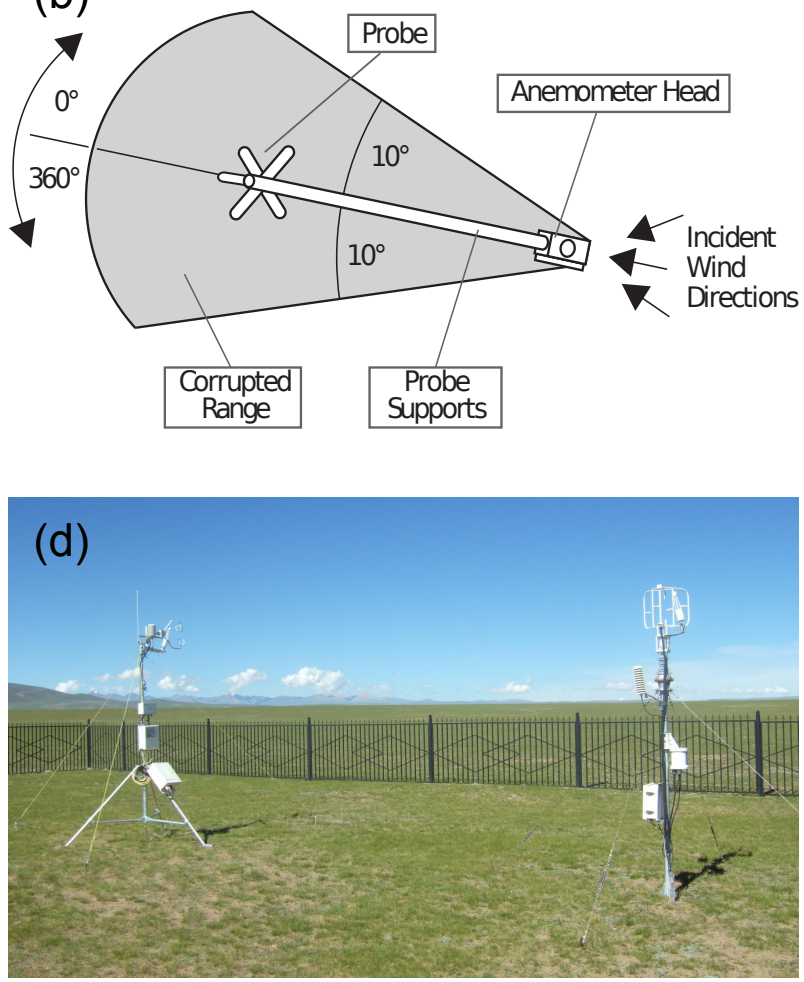

Fig. 1. (a) Kaijo-Denki, DAT 600, TR61A-probe, view from top (redrawn from Hanafusa et al., 1982). (b) Campbell CSAT3, view from top and orientation to north (Campbell Scientific Ltd., redrawn from Friebel et al., 2009); for the given orientation the disturbed sector is $170^{\circ}-$ $190^{\circ}$ in accordance with wind tunnel measurements and is therefore assumed to be smaller than in this study. (c) Kaijo-Denki, DAT 600, TR61A-probe installed at Naqu-BJ site at $20.8 \mathrm{~m}$ height on a $22-\mathrm{m}$ tall tower with the open sector to west, data set A. The picture is taken from the perspective of the tower; the sonic measuring paths appear at an angle of roughly $320^{\circ}$ (photograph: Kenji Tanaka). (d) Campbell CSAT3 (left) and Kaijo-Denki, DAT 600 TR61A probe (right) installed in 2010 at Naqu-BJ site at $3.02 \mathrm{~m}$ height with the open sector to west, data set B (photograph: Tobias Gerken).

separately and associated with the undisturbed sector, but occasionally excluded in order to yield comparisons for open sectors in the strict sense. An overview of the sensor orientation and wind sector definitions is given in Table 1. Based on these values, the DAT 600 and the CSAT3 have an overlap of their undisturbed sectors from $223^{\circ}$ to $303^{\circ}$ when including the CSAT3 front sector and from $243^{\circ}$ to $303^{\circ}$ when solely using the open sectors. The planar-fit angles calculated for all sectors described in Table 1 show generally low values, which is to be expected. The largest angles are approx. $4^{\circ}$ (data set A), which can be explained by misalignment of the sensor. They are consistent; i.e. angles for a certain sector may deviate from the respective value of the whole planarfit, but face a compensative deviation in the opposing sector. These deviations are larger for smaller sectors and vice versa. The determination of the coefficients of the planar-fit method was only done for such data classified as data with high or moderate quality (classes 1-6 according to Foken et al., 2004). Furthermore, the flat topography and the low vegetation allow for the usage of the double rotation as well.
Therefore, the double rotation is applied for comparison in this study.

\section{Results}

Because the mean vertical wind velocity is mainly affected by flow distortion, these data are investigated in detail for both instruments and data sets. Figure 2 shows that the vertical velocity without any rotation for data set $\mathrm{A}$ is larger in the sector from $150^{\circ}$ to $260^{\circ}$ due to the higher wind speeds (Fig. 2a). After normalization with the mean horizontal wind velocity, the finding agrees with a tilt error and a sinuouslike w-value distribution (Fig. 2d). Singular and negative wvalues were found for a wind direction of $130^{\circ}-135^{\circ}$, which is nearly identical to the tower position (Fig. 1c). For this analysis only data with high quality (classes 1-3 according to Foken et al., 2004) were used. When including data with moderate and low quality, the sinuous-like distribution can hardly be seen (not shown). The scatter around this distribution can be mainly attributed to data points where irregular friction occurs (red points in Fig. 2d). For data set 

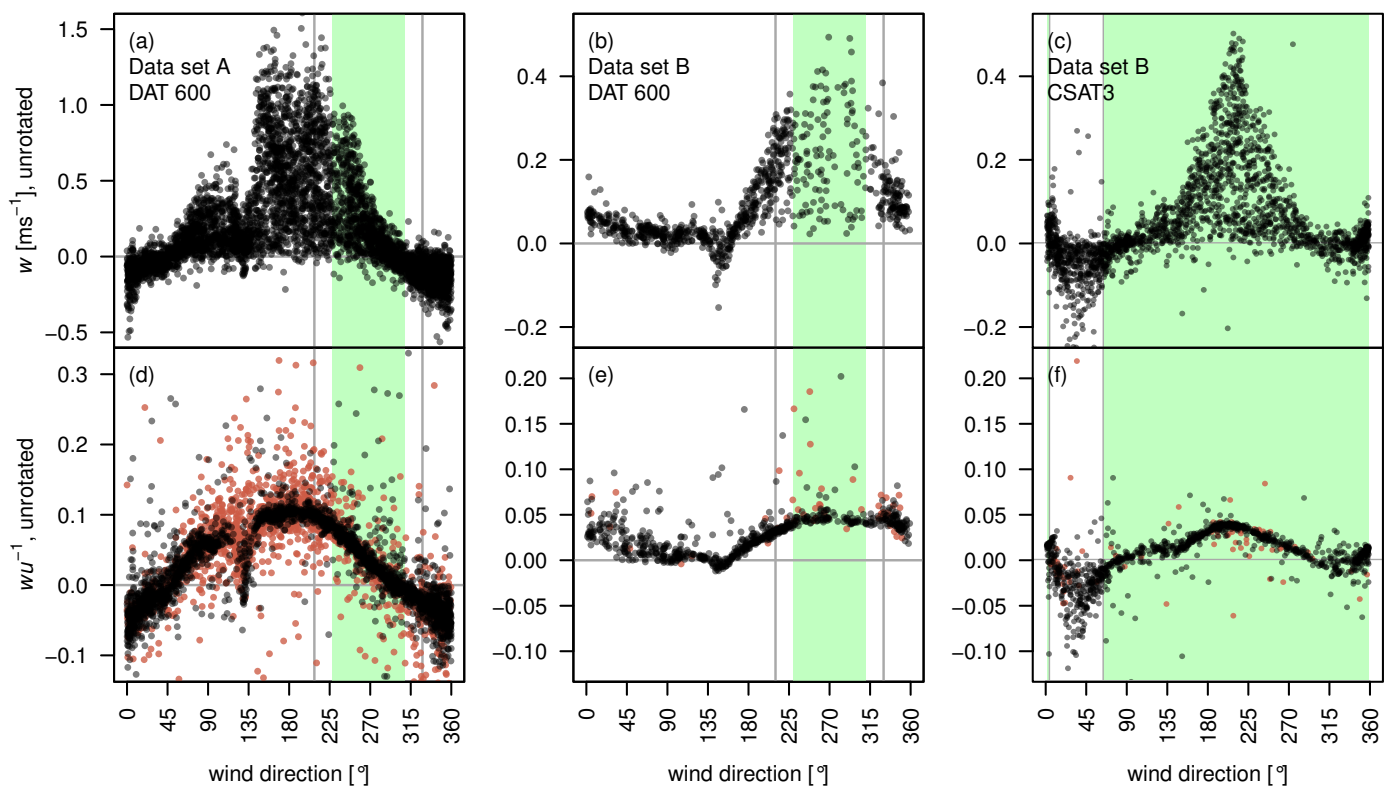

Fig. 2. Vertical wind velocity and its dependency on the wind direction for unrotated data and high data quality (flag 1-3 according to Foken et al., 2004); the upper row displays mean vertical velocity (a-c), the lower row mean vertical wind velocity normalised by the horizontal wind velocity $(\mathbf{d}-\mathbf{f}) ; w u^{-1}=0.1$ equals a tilt angle of $5.7^{\circ}$; columns represent DAT 600, data set A on the left (a,d), DAT 600, data set B in the middle (b,e) and CSAT3, data set B on the right $(\mathbf{c}, \mathbf{f})$. The green sector is the undisturbed sector, and the red points indicate data with $-\overline{u^{\prime} w^{\prime}}<0$.

Table 1. Definition of the specific wind sectors as related to sensor orientation. The open sector marks the undisturbed sector; the CSAT3 front sector is occasionally associated with the undisturbed sector.

\begin{tabular}{llllr}
\hline $\begin{array}{l}\text { Data } \\
\text { set }\end{array}$ & Device & \multicolumn{2}{l}{ Sensor-specific sectors } \\
\hline A & & Label & Orientation $\left[{ }^{\circ}\right]$ & Size $\left[{ }^{\circ}\right]$ \\
& DAT 600 & whole & $0-360$ & 360 \\
& & open & $230-310$ & 80 \\
& & disturbed & $0-230 \cup 310-360$ & 280 \\
\hline B & DAT 600 & whole & $0-360$ & 360 \\
& & open & $223-303$ & 80 \\
& & disturbed & $0-223 \cup 303-360$ & 280 \\
\hline B & CSAT3 & whole & $0-360$ & 360 \\
& & open & $0-3 \cup 63-183$ & 240 \\
& & & $\cup 243-360$ & 60 \\
& & front & $183-243$ & 60 \\
\hline
\end{tabular}

$\mathrm{B}$, smaller values occur due to the changed measurement height (Fig. 2b, c, e, f). After applying the planar-fit method for all wind directions, the vertical wind velocity is much smaller but still with a high scatter (Fig. 3a, b, c). After sector-wise planar-fit, the undisturbed sector shows considerably lower vertical wind speeds of approx. $\pm 0.1 \mathrm{~m} \mathrm{~s}^{-1}$ for data set A, DAT 600 (Fig. 3d). Only a small number of outliers are left with a higher-than-average occurrence of irreg- ular friction. Significant scatter in the data can be found at $210^{\circ}$ and $330^{\circ}$, corresponding to the anemometer construction (Fig. 1a), while the range from $120^{\circ}$ up to $140^{\circ}$ also includes the effects of the tower (Fig. 1c). Around $90^{\circ}$ the data are affected due to the flow through the probe from behind. For data set B the results for DAT 600 are similar. For CSAT3 the vertical wind velocity after rotation is reduced by the sector-wise planar-fit only in the front sector (Fig. 3e, f). In the open sector, the sector-wise planar-fit reduces vertical wind velocity mainly near the disturbed sector, but at the expense of the fit near the front sector, creating strong discontinuities there. The reason could be that flow from the CSAT3 back side might be disturbed beyond the defined sector limits and therefore still influences the open sector.

Secondly, the data set was analysed regarding the condition $-\overline{u^{\prime} w^{\prime}}<0$ for the planar-fit rotated data. The result is illustrated in Fig. 4 for high data quality, and Table 2 summarises the number of occurrences for different data quality ranges. In data set A irregular friction values are reduced by the sector-wise rotation in the optimal measuring sector (Fig. 4a, d). In the sector with flow distortion, these values were only found for wind velocities below $6 \mathrm{~m} \mathrm{~s}^{-1}$ and in the non-neutral stability range. This is similar to the findings of Gerstmann and Foken (1984) and is obviously related to flow distortion, which is more significant for low wind velocities. The double rotation decreases irregular friction velocities in the undisturbed sector even more (Fig. 4g). For data set B, similar results for the DAT 600 were obtained (Fig. 4b, e, 

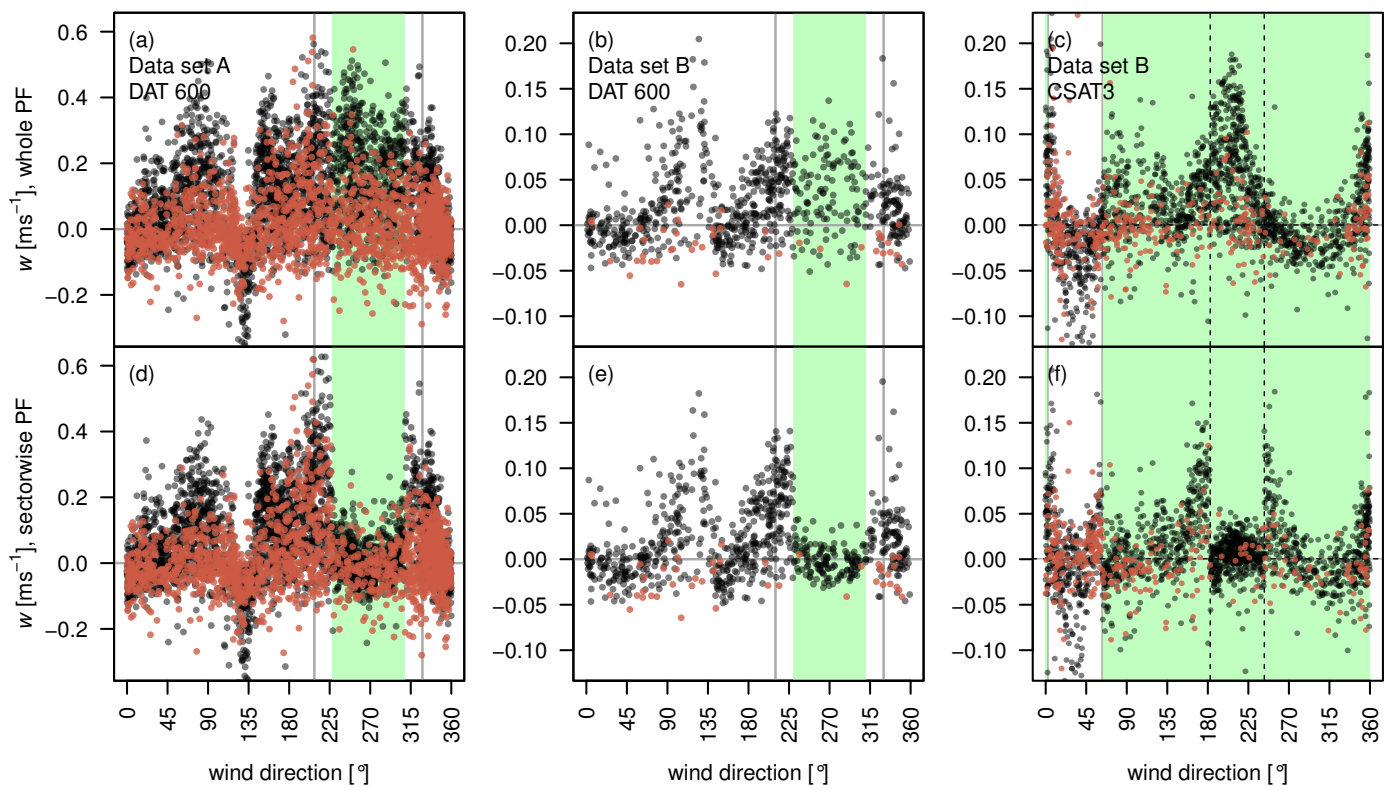

Fig. 3. Mean vertical wind velocity and its dependency on the wind direction for rotated data and high data quality (flag 1-3 according to Foken et al., 2004); the upper row displays mean vertical velocity rotated for the whole period (a-c), the lower row mean vertical wind velocity rotated sector-wise (d-f); columns represent DAT 600, data set A on the left (a,d), DAT 600, data set B in the middle (b,e) and CSAT3, data set B on the right $(\mathbf{c}, \mathbf{f})$. The green sector is the undisturbed sector and the red points indicate data with $-\overline{u^{\prime} w^{\prime}}<0$; dashed lines for CSAT3 indicate the front sector, which is rotated separately.

h), but many fewer occurrences of irregular friction velocity were found due to the low measuring height. For high data quality the rare incidences prohibit an interpretation of the differences, but both the sector-wise planar-fit and the double rotation yield substantial reduction compared to the whole planar-fit when including moderate and low data quality (Table 2). Also, for CSAT3, data with $-\overline{u^{\prime} w^{\prime}}<0$ occur mainly in the disturbed sector (Fig. 4c, f, i) and for low data quality (Table 2), although the relative frequency in the open sector is in general larger than for DAT 600, data set B. The sector-wise planar-fit yields substantial reduction of irregular friction velocities especially in the front sector (between the dashed lines). In the open sector, however, the improvement is small and the double rotation fails to reduce such incidents for high and moderate data quality. The reduction of irregular friction velocities by the sector-wise planar-fit increases when including the CSAT3 front sector. When no separate rotation for the front sector of the CSAT3 is made, however, there is nearly no difference visible between whole and sector-wise rotation (not shown). This suggests that the disturbed sector should be excluded but that the front and side sectors should be rotated separately.

The friction velocity and the sensible heat flux were compared when using only one rotation for the whole data set versus sector-wise rotation (Fig. 5a, b). Slope and offset were obtained using a geometric mean regression (e.g. Helsel and Hirsch, 2002). The data of the disturbed sector were discarded, and only data with high data quality (classes 1-
Table 2. Percentage of irregular data with $-\overline{u^{\prime} w^{\prime}}<0$ for only the undisturbed sector (for sector definitions see Table 1) and different data qualities (QC flag) according to Foken et al. (2004).

\begin{tabular}{lllrrrrrr}
\hline $\begin{array}{l}\text { Data } \\
\text { set }\end{array}$ & Device & $\begin{array}{l}\text { QC } \\
\text { flag }\end{array}$ & \multicolumn{2}{c}{$\begin{array}{c}\text { Sector-wise } \\
\text { planar-fit }\end{array}$} & \multicolumn{2}{c}{$\begin{array}{c}\text { Whole } \\
\text { planar-fit }\end{array}$} & \multicolumn{2}{c}{$\begin{array}{c}\text { Double } \\
\text { rotation }\end{array}$} \\
& & & N & irr.* & N & irr.* & N & irr. $^{*}$ \\
\hline A & DAT & $1-3$ & 964 & 20 & 920 & 34 & 1035 & 14 \\
& 600 & $1-6$ & 1795 & 25 & 1766 & 43 & 1960 & 17 \\
& & $1-8$ & 2056 & 26 & 2056 & 46 & 2056 & 18 \\
\hline B & DAT & $1-3$ & 140 & 2.1 & 121 & 3.3 & 146 & 1.4 \\
& 600 & $1-6$ & 209 & 2.4 & 182 & 8.8 & 245 & 1.6 \\
& & $1-8$ & 302 & 3.0 & 302 & 17.2 & 302 & 1.3 \\
\hline B & CSAT3 & $1-3$ & 617 & 3.9 & 609 & 4.3 & 698 & 5.7 \\
& nF & $1-6$ & 836 & 9.2 & 814 & 10.8 & 913 & 10.4 \\
& & $1-8$ & 1137 & 15.6 & 1138 & 17.5 & 1138 & 12.3 \\
\hline B & CSAT3 & $1-3$ & 832 & 3.4 & 795 & 4.4 & 916 & 5.0 \\
& sF & $1-6$ & 1154 & 7.4 & 1110 & 9.6 & 1256 & 9.1 \\
& & $1-8$ & 1608 & 12.0 & 1609 & 15.9 & 1609 & 10.5 \\
\hline
\end{tabular}

* irr: irregular occurrences of friction $-\overline{u^{\prime} w^{\prime}}<0$ in $\%$

a $\mathrm{nF}$ : no front sector, front sector excluded from undisturbed sector

b sF: front sector included but rotated separately in the sector-wise planar-fit.

3) are shown for data set A and DAT 600. When including moderate data quality (classes 4-6), the scatter is larger but the tendency of the regressions does not change (not shown). The friction velocity is enhanced by $10 \%$ through the sector-wise planar-fit rotation (Fig. 5, a), while the sensible heat flux was obviously not different for both planar-fit rotations (Fig. 5, b). The double rotation yields much larger 

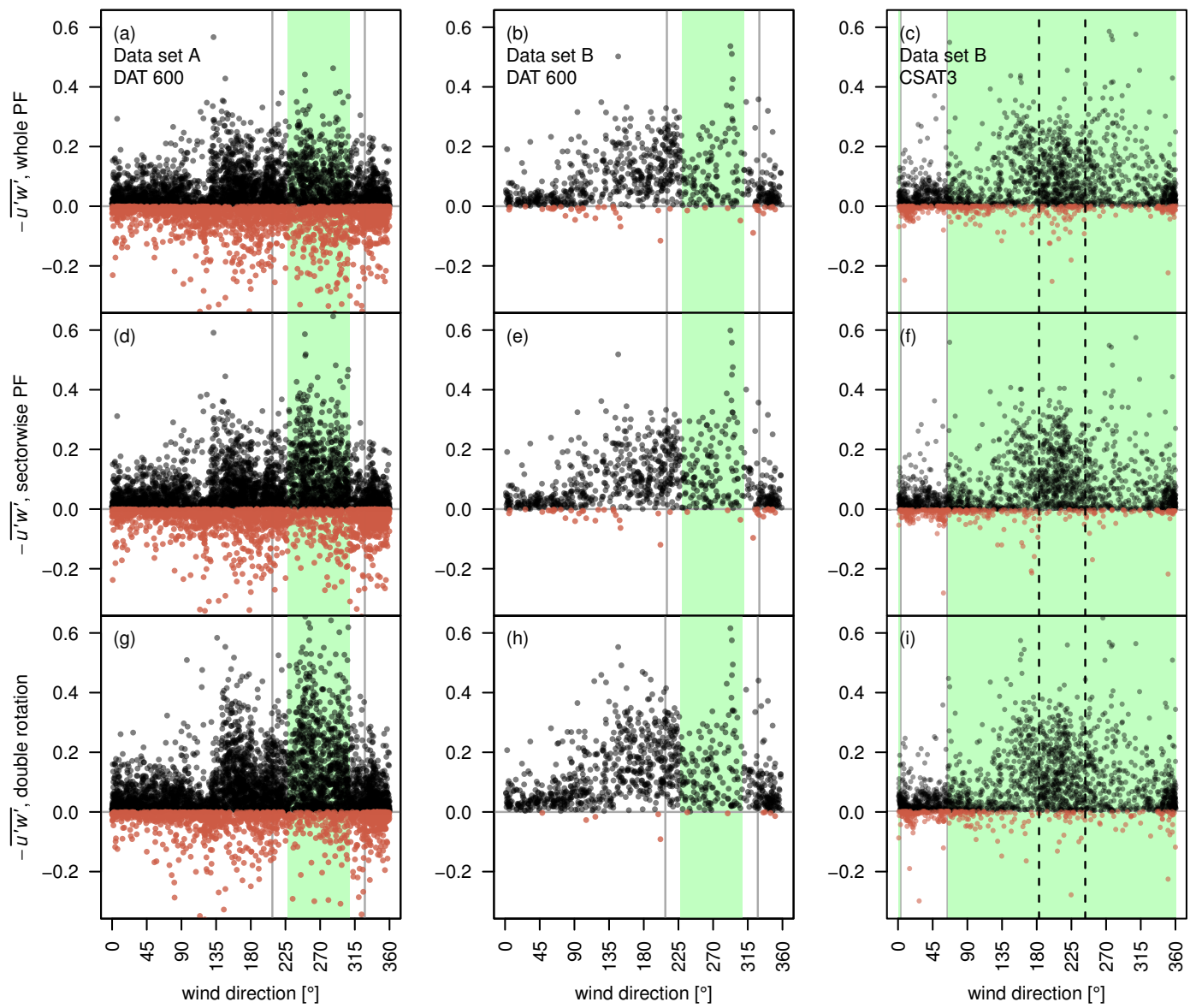

Fig. 4. Covariance $-\overline{u^{\prime} w^{\prime}}$ and its dependency on the wind direction for rotated data and high data quality (flag $1-3$ according to Foken et al., 2004); The upper row displays $-\overline{u^{\prime} w^{\prime}}$, data rotated for the whole period $(\mathbf{a}-\mathbf{c})$, the middle row $-\overline{u^{\prime} w^{\prime}}$, data rotated sector-wise $(\mathbf{d}-\mathbf{f})$, the lower row $-\overline{u^{\prime} w^{\prime}}$, using double rotation (g-i); columns represent DAT 600, data set A on the left (a, d, g), DAT 600, data set B in the middle $(\mathbf{b}, \mathbf{e}, \mathbf{h})$ and CSAT3, data set B on the right $(\mathbf{c}, \mathbf{f}, \mathbf{i})$. The green sector is the undisturbed sector and the red points indicate data with $-\overline{u^{\prime} w^{\prime}}<0$; dashed lines for CSAT3 indicate the front sector, which is rotated separately.

friction velocities than the sector-wise planar-fit (Fig. 5, c). For moderate and low data quality, even unrealistic values of $u_{*}>2 \mathrm{~m} \mathrm{~s}^{-1}$ occur due to double rotation. The sensible heat flux is not affected for high data quality, but the number of outliers again increases with data quality, complicating accurate slope estimation. The results for both data sets and instruments are shown in Table 3. In data set B the DAT 600 behaves similarly as in data set $\mathrm{A}$, but the friction velocity is increased by only $4-5 \%$. The friction velocity from CSAT3 is not markedly affected, even if the front sector is included. Compared to the double rotation, the sector-wise planar-fit slightly increases the friction velocity for data set B, DAT 600, and decreases the friction velocity for CSAT3. The sensible heat flux is again not affected. Few outliers occurred for double rotation, which could be easily removed by applying consistency limits to fluxes with $u_{*}>2 \mathrm{~m} \mathrm{~s}^{-1}$ and $Q_{\mathrm{H}}>1000 \mathrm{Wm}^{-2}$.

The results confirm the findings by Hong et al. (2004) for the Naqu-BJ site: "There was little difference in kine- matic sensible heat fluxes (not shown) [...] However, $\overline{u^{\prime} w^{\prime}}$ from KD was $5 \%$ smaller than that from CS" (KD: KaijoDenki, CS: Campbell Scientific CSAT3). Hong et al. (2004) could not give an explanation for these differences and corrected the KD data with the CS measurements. Contrary to Hong et al. (2004), our findings for $\sigma_{\mathrm{u}}$ and $\sigma_{\mathrm{v}}$ showed no considerable effect of the rotation method.

\section{Conclusions}

If non-omnidirectional sonic anemometers are not moved into the mean wind direction for each measuring series or the data are not selected only for the open sector of the anemometer, the coordinate rotation or planar-fit method must be applied with care. For the open sector of the anemometer, a separate planar-fit should be used. All data from the other sector must be flagged as low data quality, especially because, for low wind velocities, irregular friction 

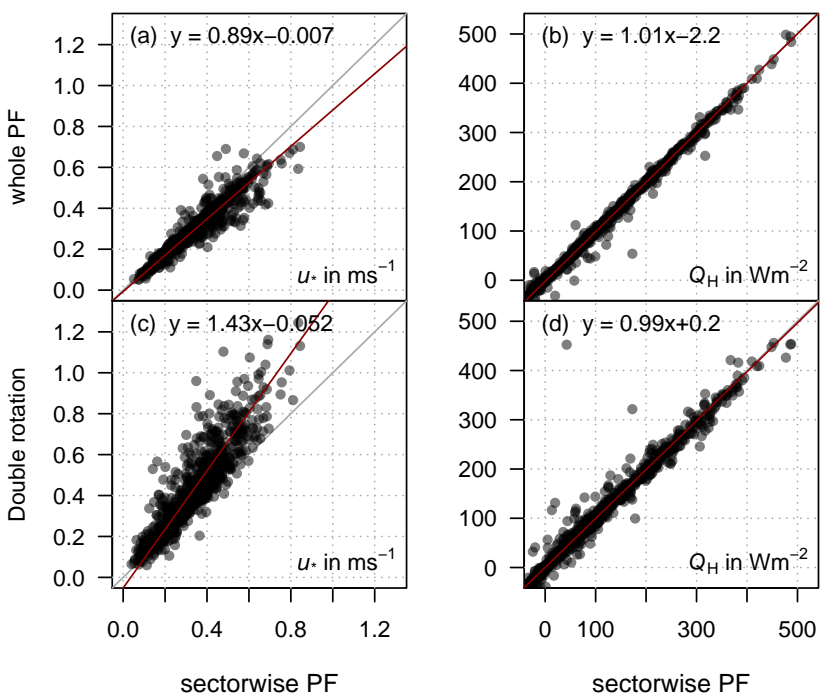

Fig. 5. Comparison of the sector-wise planar-fit rotation vs. planarfit rotation for all wind directions $(\mathbf{a}, \mathbf{b})$ and vs. double rotation $(\mathbf{c}, \mathbf{d})$ for the friction velocity $(\mathbf{a}, \mathbf{c})$ and the sensible heat flux $(\mathbf{b}, \mathbf{d})$; data set A, DAT 600, was used, only from the undisturbed sector and with high quality (flag 1-3 according to Foken et al., 2004).

Table 3. Regression analysis of the friction velocity and sensible heat flux using geometric mean regression for different data qualities (QC flag) according to Foken et al. (2004). Only data from the undisturbed sector are used. For sector definitions, see Table 1.

\begin{tabular}{|c|c|c|c|c|}
\hline \multirow[t]{2}{*}{$\begin{array}{l}\text { Data } \\
\text { set }\end{array}$} & \multirow[t]{2}{*}{ Device } & \multirow[t]{2}{*}{$\begin{array}{l}\text { QC } \\
\text { flag }\end{array}$} & $\begin{array}{l}\text { Friction velocity } \\
{\left[\mathrm{m} \mathrm{s}^{-1}\right]}\end{array}$ & $\begin{array}{c}\text { Sensible heat flux } \\
{\left[\mathrm{W} \mathrm{m}^{-2}\right]}\end{array}$ \\
\hline & & & $R^{2}$ & $R^{2}$ \\
\hline
\end{tabular}

Regression $y=a x+b$ with

$x$ : sector-wise planar-fit, $y$ : planar-fit for the whole sector

\begin{tabular}{lllllllll}
\hline A & DAT & $1-3$ & 0.89 & -0.007 & 0.87 & 1.01 & -2.2 & 0.98 \\
& 600 & $1-6$ & 0.85 & -0.003 & 0.84 & 1.01 & -3.5 & 0.95 \\
\hline B & DAT & $1-3$ & 0.96 & -0.011 & 0.99 & 0.99 & 0.3 & 0.99 \\
& 600 & $1-6$ & 0.95 & -0.015 & 0.97 & 0.99 & 0.3 & 0.99 \\
\hline B & CSAT3 & $1-3$ & 1.02 & -0.005 & 0.99 & 1.01 & -0.4 & 0.99 \\
& $\mathrm{nF}^{\mathrm{a}}$ & $1-6$ & 1.01 & -0.004 & 0.99 & 1.00 & -0.1 & 0.99 \\
\hline $\mathrm{B}$ & $\mathrm{CSAT3}$ & $1-3$ & 1.00 & -0.006 & 0.98 & 1.00 & 0.0 & 0.99 \\
& $\mathrm{sF}$ & $1-6$ & 0.99 & -0.003 & 0.97 & 1.00 & 0.1 & 0.97 \\
\hline
\end{tabular}

Regression $y=a x+b$ with

$x$ : sector-wise planar-fit, $y$ : double rotation

\begin{tabular}{lllllllll}
\hline A & DAT & $1-3$ & 1.43 & -0.052 & 0.80 & 0.99 & 0.2 & 0.96 \\
& 600 & $1-6$ & $1.66^{\mathrm{c}}$ & -0.078 & 0.70 & $1.17^{\mathrm{c}}$ & -6.9 & 0.74 \\
\hline $\mathrm{B}$ & DAT & $1-3$ & 0.97 & 0.039 & 0.89 & 1.01 & -0.3 & 0.99 \\
& 600 & $1-6$ & 0.98 & 0.039 & 0.87 & 1.02 & -0.4 & 0.99 \\
\hline $\mathrm{B}$ & $\mathrm{CSAT}^{2}$ & $1-3$ & 1.05 & 0.005 & 0.98 & 1.02 & -0.4 & 0.98 \\
& $\mathrm{nF}^{\mathrm{a}}$ & $1-6$ & 1.06 & 0.008 & 0.96 & 1.02 & -0.9 & 0.95 \\
\hline $\mathrm{B}$ & $\mathrm{CSAT}^{2}$ & $1-3$ & 1.04 & 0.005 & 0.98 & 1.01 & -0.1 & 0.98 \\
& $\mathrm{sF}$ & $1-6$ & 1.05 & 0.006 & 0.95 & 1.02 & -1.1 & 0.96
\end{tabular}

${ }^{a} \mathrm{nF}$ : no front sector, front sector excluded from undisturbed sector

b $\mathrm{sF}$ : front sector included but rotated separately in the sector-wise planar-fit

${ }^{\mathrm{c}}$ slope sensitive to several outliers occurring in data from double rotation.
Table 4. Regression analysis of the friction velocity and sensible heat flux using geometric mean regression for different data qualities (QC flag) according to Foken et al. (2004). Only data from the undisturbed sector are used. For sector definitions, see Table 1.

\begin{tabular}{|c|c|c|c|c|c|c|c|}
\hline \multirow[t]{2}{*}{ Rotation method } & \multirow[t]{2}{*}{$\begin{array}{l}\text { QC } \\
\text { flag }\end{array}$} & \multicolumn{3}{|c|}{$\begin{array}{l}\text { Friction velocity } \\
\qquad\left[\mathrm{ms}^{-1}\right]\end{array}$} & \multicolumn{3}{|c|}{$\begin{array}{c}\text { Sensible heat flux } \\
{\left[\mathrm{W} \mathrm{m}^{-2}\right]}\end{array}$} \\
\hline & & $a$ & $b$ & $R^{2}$ & $a$ & $b$ & $R^{2}$ \\
\hline \multicolumn{8}{|c|}{$\begin{array}{r}\text { Regression } y=a x+b \text { with } \\
y \text { : DAT } 600 \text {, data set } \mathrm{B},\end{array}$} \\
\hline Sector-wise planar-fit & $\begin{array}{l}1-3 \\
1-6\end{array}$ & $\begin{array}{l}1.00 \\
1.00\end{array}$ & $\begin{array}{l}0.004 \\
0.000\end{array}$ & $\begin{array}{l}0.97 \\
0.96\end{array}$ & $\begin{array}{l}1.03 \\
0.92\end{array}$ & $\begin{array}{r}-4.3 \\
2.9\end{array}$ & $\begin{array}{l}0.95 \\
0.81\end{array}$ \\
\hline Whole planar-fit & $\begin{array}{l}1-3 \\
1-6\end{array}$ & $\begin{array}{l}0.94 \\
0.95\end{array}$ & $\begin{array}{l}-0.006 \\
-0.019\end{array}$ & $\begin{array}{l}0.97 \\
0.95\end{array}$ & $\begin{array}{l}1.01 \\
0.93\end{array}$ & $\begin{array}{r}-5.7 \\
1.0\end{array}$ & $\begin{array}{l}0.93 \\
0.87\end{array}$ \\
\hline Double rotation & $\begin{array}{l}1-3 \\
1-6\end{array}$ & $\begin{array}{l}0.97 \\
1.02\end{array}$ & $\begin{array}{l}0.016 \\
0.000\end{array}$ & $\begin{array}{l}0.93 \\
0.86\end{array}$ & $\begin{array}{l}1.01 \\
0.91\end{array}$ & $\begin{array}{r}-3.4 \\
4.0\end{array}$ & $\begin{array}{l}0.95 \\
0.82\end{array}$ \\
\hline $\begin{array}{r}\text { Regression } y=a x+l \\
y \text { : DAT } 600 \text {, data }\end{array}$ & $\begin{array}{l}\text { vith } \\
\text { et } B, x\end{array}$ & $\mathrm{CSA}^{\prime}$ & dats c & fro & or in & Ided & \\
\hline Sector-wise planar-fit & $\begin{array}{l}1-3 \\
1-6\end{array}$ & $\begin{array}{l}1.01 \\
1.01\end{array}$ & $\begin{array}{l}-0.002 \\
-0.007\end{array}$ & $\begin{array}{l}0.95 \\
0.94\end{array}$ & $\begin{array}{l}0.99 \\
0.95\end{array}$ & $\begin{array}{r}-0.7 \\
1.5\end{array}$ & $\begin{array}{l}0.95 \\
0.89\end{array}$ \\
\hline Whole planar-fit & $\begin{array}{l}1-3 \\
1-6\end{array}$ & $\begin{array}{l}0.94 \\
0.93\end{array}$ & $\begin{array}{l}-0.007 \\
-0.016\end{array}$ & $\begin{array}{l}0.95 \\
0.91\end{array}$ & $\begin{array}{l}0.97 \\
0.95\end{array}$ & $\begin{array}{r}-1.1 \\
0.1\end{array}$ & $\begin{array}{l}0.92 \\
0.89\end{array}$ \\
\hline Double rotation & $\begin{array}{l}1-3 \\
1-6\end{array}$ & $\begin{array}{l}0.97 \\
0.95\end{array}$ & $\begin{array}{l}0.009 \\
0.013\end{array}$ & $\begin{array}{l}0.89 \\
0.81\end{array}$ & $\begin{array}{l}0.97 \\
0.94\end{array}$ & $\begin{array}{l}0.9 \\
2.6\end{array}$ & $\begin{array}{l}0.90 \\
0.85\end{array}$ \\
\hline
\end{tabular}

data are possible. The problem is not limited to the KaijoDenki DAT 600 TR61A probe but is similar in the case of other sonic anemometer types, such as CSAT3 (Campbell Scientific Ltd.), with a much larger open sector of $340^{\circ}$. By applying the data quality scheme according to Foken et al. (2004, Table 9.5, but not included in TK3 software), the data from the remaining disturbed sector of $20^{\circ}$ (CSAT3) are flagged as containing errors (flag 9). But this selection must be applied before the planar fit rotation. However, a substantial fraction of irregular friction data cannot be eliminated by a sector-wise planar-fit. Furthermore, the vertical wind velocity is also influenced by the CSAT3 probe supporting structures for wind directions from the front sector. A separate planar-fit rotation for this sector substantially reduces mean vertical wind velocity in this sector and also has an effect on the friction velocity.

Published data of the Naqu-BJ site (Hong et al., 2004; Li et al., 2006) or other sites with Kaijo-Denki, TR61A-probe sonic anemometers, should be used with care. Fortunately, only the friction velocity and standard deviations of the wind components are affected, with no substantial influence being found for scalar fluxes. Nevertheless, the separate planarfit rotation should be used for all data. If the coefficients of the planar-fit rotation for both instruments were only determined for the undisturbed sector, differences in friction velocity between DAT 600 and CSAT3 can be substantially reduced (Table 4). Therefore, a correction of DAT 600 data according to a comparison with a CSAT3, as done by Hong et al. (2004), does not seem to be necessary for high quality flux data from the undisturbed sector. The double rotation yields reasonable results for high data quality, but the 
occurrence of outliers and larger scatter (lower coefficients of determination in Table 4) confirms the mentioned problem of potential overrotation.

The CSAT3 is one of the best rated sonic anemometers available (Mauder et al., 2007). This study does not call these findings into question, but rather it demonstrates some problems related to the CSAT3 probe structures, which could not be conclusively clarified. Therefore, more thorough experiments should be conducted regarding influence of the CSAT3 geometry on the flow field, including information about internal sensor-specific corrections as pointed out by Burns et al. (2012).

Acknowledgements. This work is financed by the German Research Foundation (DFG) Priority Programme 1372 TiP and the Chinese National Key Programme for Developing Basic Sciences (2010CB951703). It is further financed by CEOP-AEGIS, a Collaborative Project/Small or medium-scale focused research project - Specific International Co-operation Action financed by the European Commission under FP7 topic ENV.2007.4.1.4.2 "Improving observing systems for water resource management" and coordinated by the University of Strasbourg, France. The authors acknowledge support from the National Natural Science Foundation of China (Grant No. 41175008). Furthermore, this publication is funded by the DFG and the University of Bayreuth in the funding programme Open Access Publishing.

Edited by: A. Stoffelen

\section{References}

Burns, S. P., Horst, T. W., Jacobsen, L., Blanken, P. D., and Monson, R. K.: Using sonic anemometer temperature to measure sensible heat flux in strong winds, Atmos. Meas. Tech., 5, 20952111, doi:10.5194/amt-5-2095-2012, 2012.

Dyer, A. J.: Flow distortion by supporting structures, Bound.-Lay. Meteorol., 20, 243-251, doi:10.1007/BF00119905, 1981.

Finnigan, J. J.: A re-evaluation of long-term flux measurement techniques, Part II: Coordinate systems, Bound.-Lay. Meteorol., 113, 1-41, doi:10.1023/B:BOUN.0000037348.64252.45, 2004.

Finnigan, J., Clement, R., Malhi, Y., Leuning, R., and Cleugh, H.: A re-evaluation of long-term flux measurement techniques, Part I: Averaging and Coordinate Rotation, Bound.-Lay. Meteorol., 107, 1-48, doi:10.1023/A:1021554900225, 2003.

Foken, T., Zelený, J., Zubkovskij, S. L., and Fedorov, M. M.: Comparison of turbulence measuring instruments, in: Structure of the Boundary Layer over Non-Homogeneous Terrain, Proceedings of the Field Experiment KOPEX-86, Prague, 25-35, 1988.

Foken, T., Göckede, M., Mauder, M., Mahrt, L., Amiro, B., and Munger, J.: Post-field data quality control, in: Handbook of Micrometeorology: a Guide for Surface Flux Measurement and Analysis, edited by: Lee, X., Massman, W., and Law, B., Kluwer, Dordrecht, 181-208, 2004.

Foken, T., Aubinet, M., and Leuning, R.: The eddy covariance method, in: Eddy Covariance: a Practical Guide to Measurement and Data Analysis, edited by: Aubinet, M., Vesala, T., and Pa- pale, D., Springer Atmospheric Sciences, Springer, The Netherlands, doi:10.1007/978-94-007-2351-1_1, 1-19, 2012a.

Foken, T., Leuning, R., Oncley, S. R., Mauder, M., and Aubinet, M.: Corrections and data quality control, in: Eddy Covariance: a Practical Guide to Measurement and Data Analysis, edited by: Aubinet, M., Vesala, T., and Papale, D., Springer Atmospheric Sciences, Springer, The Netherlands, doi:10.1007/978-94-0072351-1_4, 85-131, 2012b.

Friebel, H. C., Herrington, T. O., and Benilov, A. Y.: Evaluation of the flow distortion around the Campbell scientific CSAT3 sonic anemometer relative to incident wind direction, J. Atmos. Ocean. Tech., 26, 582-592, doi:10.1175/2008JTECHO550.1, 2009.

Gerstmann, W. and Foken, T.: Eigenschaften des Ultraschallanemometers der Firma Kaijo-Denki auf Grund der Ergebnisse von MESP-81 (Properties of the sonic anemometer of the KaijoDenki company on the basis of the results of the experiment ITCE-81), Geod. Geophys. Veröff., R. II, 26, 30-35, 1984.

Göckede, M., Foken, T., Aubinet, M., Aurela, M., Banza, J., Bernhofer, C., Bonnefond, J. M., Brunet, Y., Carrara, A., Clement, R., Dellwik, E., Elbers, J., Eugster, W., Fuhrer, J., Granier, A., Grünwald, T., Heinesch, B., Janssens, I. A., Knohl, A., Koeble, R., Laurila, T., Longdoz, B., Manca, G., Marek, M., Markkanen, T., Mateus, J., Matteucci, G., Mauder, M., Migliavacca, M., Minerbi, S., Moncrieff, J., Montagnani, L., Moors, E., Ourcival, J.-M., Papale, D., Pereira, J., Pilegaard, K., Pita, G., Rambal, S., Rebmann, C., Rodrigues, A., Rotenberg, E., Sanz, M. J., Sedlak, P., Seufert, G., Siebicke, L., Soussana, J. F., Valentini, R., Vesala, T., Verbeeck, H., and Yakir, D.: Quality control of CarboEurope flux data - Part 1: Coupling footprint analyses with flux data quality assessment to evaluate sites in forest ecosystems, Biogeosciences, 5, 433-450, doi:10.5194/bg-5-433-2008, 2008.

Hanafusa, T., Fujitani, T., Kobori, Y., and Mitsuta, Y.: A new type sonic anemometer-thermometer for field operation, Pap. Meteorol. Geophys., 33, 1-19, 1982.

Helsel, D. and Hirsch, R. M.: Statistical Methods in Water Resources, Techniques of Water Resources Investigations, Book 4, chapter A3, US Geological Survey, 522 pp., available at: http://water.usgs.gov/pubs/twri/twri4a3/, 2002.

Hong, J., Choi, T., Ishikawa, H., and Kim, J.: Turbulence structures in the near-neutral surface layer on the Tibetan Plateau, Geophys. Res. Lett., 31, L15106, doi:10.1029/2004GL019935, 2004.

Kaimal, J. C. and Finnigan, J. J.: Atmospheric Boundary Layer Flows: their Structure and Measurement, Oxford University Press, New York, NY, 289 pp., 1994.

Lee, X.: On micrometeorological observations of surface-air exchange over tall vegetation, Agr. Forest Meteorol., 91, 39-49, doi:10.1016/S0168-1923(98)00071-9, 1998.

Lee, X., Finnigan, J., and Paw U, K.: Coordinate systems and flux bias error, in: Handbook of micrometeorology: A guide for surface flux measurement and analysis, edited by: Lee, X., Massman, W., and Law, B., 33-66, Kluwer, Dordrecht, 2004.

Li, M., Ma, Y., Ma, W., Hu, Z., Ishikawa, H., Su, Z., and Sun, F.: Analysis of turbulence characteristics over the Northern Tibetan Plateau area, Adv. Atmos. Sci., 23, 579-585, doi:10.1007/s00376-006-0579-z, 2006.

Mauder, M. and Foken, T.: Documentation and Instruction Manual of the Eddy Covariance Software Package TK2, Work Report University of Bayreuth, Dept. of Micrometeorology, ISSN 
1614-8916, 26, 42 pp., available at: http://opus.ub.uni-bayreuth. de/opus4-ubbayreuth/frontdoor/index/index/docId/639, 2004.

Mauder, M. and Foken, T.: Documentation and Instruction Manual of the Eddy-Covariance Software Package TK3, Work Report University of Bayreuth, Dept. of Micrometeorology, ISSN 1614-8916, 46, 58 pp., available at: http://opus.ub.uni-bayreuth. de/opus4-ubbayreuth/frontdoor/index/index/docId/681, 2011.

Mauder, M., Oncley, S., Vogt, R., Weidinger, T., Ribeiro, L., Bernhofer, C., Foken, T., Kohsiek, W., De Bruin, H., and Liu, H.: The energy balance experiment EBEX-2000. Part II: Intercomparison of eddy-covariance sensors and post-field data processing methods, Bound.-Lay. Meteorol., 123, 29-54, doi:10.1007/s10546006-9139-4, 2007.

Mauder, M., Foken, T., Clement, R., Elbers, J. A., Eugster, W., Grünwald, T., Heusinkveld, B., and Kolle, O.: Quality control of CarboEurope flux data - Part 2: Inter-comparison of eddy-covariance software, Biogeosciences, 5, 451-462, doi:10.5194/bg-5-451-2008, 2008

Ono, K., Mano, M., Miyata, A., and Inoue, Y.: Applicability of the Planar Fit Technique in Estimating Surface Fluxes over Flat Terrain using Eddy Covariance, J. Agric. Meteorol., 64, 121-130, doi:10.2480/agrmet.64.3.5, 2008.

Paw U, K., Baldocchi, D., Meyers, T., and Wilson, K.: Correction Of Eddy-Covariance Measurements Incorporating Both Advective Effects And Density Fluxes, Bound.-Lay. Meteorol., 97, 487-511, doi:10.1023/A:1002786702909, 2000.
Rebmann, C., Kolle, O., Heinesch, B., Queck, R., Ibrom, A., and Aubinet, M.: Data acquisition and flux calculations, in: Eddy Covariance: a Practical Guide to Measurement and Data Analysis, edited by: Aubinet, M., Vesala, T., and Papale, D. Springer Atmospheric Sciences, Springer, The Netherlands, doi:10.1007/978-94-007-2351-1_3, 59-83, 2012.

Siebicke, L. and Serafimovich, A.: UltraschallanemometerÜberprüfung im Windkanal der TU Dresden, Work Report University of Bayreuth, Dept. of Micrometeorology, ISSN 16148916, 30, 42 pp., available at: http://opus.ub.uni-bayreuth.de/ opus4-ubbayreuth/frontdoor/index/index/docId/628, 2007.

Siebicke, L., Hunner, M., and Foken, T.: Aspects of $\mathrm{CO}_{2}$ advection measurements, Theor. Appl. Climatol., 109, 109-131, doi:10.1007/s00704-011-0552-3, 2012.

Wilczak, J., Oncley, S., and Stage, S.: Sonic Anemometer Tilt Correction Algorithms, Bound.-Lay. Meteorol., 99, 127-150, doi:10.1023/A:1018966204465, 2001.

Yuan, R., Kang, M., Park, S.-B., Hong, J., Lee, D., and Kim, J.: Expansion of the planar-fit method to estimate flux over complex terrain, Meteorol. Atmos. Phys., 110, 123-133, doi:10.1007/s00703-010-0113-9, 2011. 